\title{
Scolia
}

Revue de linguistique

\section{L'(in)définitude des lectures relatives des superlatifs de qualité et de quantité}

(In)definiteness in the Relative Readings of Quality and Quantity Superlatives

\section{Carmen Dobrovie-Sorin}

\section{(2) OpenEdition \\ 1 Journals}

\section{Electronic version}

URL: https://journals.openedition.org/scolia/1898

DOI: $10.4000 /$ scolia. 1898

ISSN: 2677-4224

\section{Publisher}

Presses universitaires de Strasbourg

\section{Printed version}

Date of publication: 9 July 2021

Number of pages: 15-37

ISBN: 979-10-344-0091-1

ISSN: 1253-9708

\section{Electronic reference}

Carmen Dobrovie-Sorin, " $L$ '(in)définitude des lectures relatives des superlatifs de qualité et de quantité", Scolia [Online], 35 | 2021, Online since 09 July 2021, connection on 13 July 2021. URL: http:// journals.openedition.org/scolia/1898 ; DOI: https://doi.org/10.4000/scolia.1898

\section{(c) (i) (3)(2)}

Les contenus de la revue Scolia sont mis à disposition selon les termes de la Licence Creative Commons Attribution - Pas d'Utilisation Commerciale - Partage dans les Mêmes Conditions 4.0 International. 


\title{
L'(in)définitude des lectures relatives des superlatifs de qualité et de quantité
}

\author{
Carmen Dobrovie-SORIN* \\ CNRS - Laboratoire de Linguistique Formelle, Université de Paris \\ sorin.carmen2@gmail.com
}

\section{Introduction}

The empirical focus of this article is a distributional contrast that can be observed in certain languages between the relative readings of quality superlatives and those of the quantity superlative MOST: the former require the definite article whereas the latter ban it. Assuming that (at least) in languages with articles the $\mathrm{D}$-level is always projected, those DPs that embed MOST would be necessarily headed by a null determiner. Granting that the definite article contributes uniqueness, its absence/presence indicates that the uniqueness of the external argument of the DP is required with quality superlatives (and crucially, even on their relative readings), but not with quantity superlatives. This paper proposes an explanation for this contrast that is formulated within the so-called "scope" theory of superlatives (originating with Heim (1985, 1999) and Szabolcsi (1986)), according to which the difference between the absolute and relative readings of superlatives is a matter of scope ambiguity that is represented at LF.

\section{Heim's (1999) analyses of superlatives}

Any analysis of superlatives needs to account for the difference between absolute and relative readings:

* Thanks go to Patricia Cabredo-Hofherr, Ion Giurgea and Peter Hallman for helpful comments on the first version of this paper. 
1) John bought the most expensive ring.

a. Out of all the rings in a given shop John bought the most expensive one.

b. Out of a given group of buyers it's John who bought the most expensive ring.

The information introduced by "out of" in the paraphrases above is intuitively speaking the "comparison class" of the superlative: in the (a) interpretation we compare rings (in a contextually restricted set, e.g., the rings in a shop), whereas in (b) we compare rings bought by various buyers (equivalently, we may say that we compare buyers of expensive rings).

Following Heim (1999), theoreticians agree on assuming that the absolute and relative readings of superlatives rely on a uniform denotation of the superlative morpheme EST (this notation will be used for the various crosslinguistic realizations of superlative-dedicated morphemes). According to the formula in (2), which is a lambdanotation version of Heim's formula 10, EST takes three arguments: the comparison class notated $\mathrm{C}$, which ranges over sets of individuals (type $<\mathrm{e}, \mathrm{t}>$ ), a gradable predicate $\mathrm{R}$ (a function from degrees into sets of individuals, type $\langle\mathrm{d}\langle\mathrm{e}, \mathrm{t}\rangle>$ ) and the external argument $\mathrm{x}$ (type e):

2) $[[\mathrm{EST}]]=\lambda \mathrm{C} \lambda \mathrm{R} \lambda \mathrm{x} \cdot \exists \mathrm{d}[\mathrm{R}(\mathrm{d})(\mathrm{x}) \wedge \forall \mathrm{y}[\mathrm{y} \in \mathrm{C} \wedge \mathrm{y} \neq \mathrm{x} \rightarrow \neg \mathrm{R}(\mathrm{d})(\mathrm{y})]]$

According to (2), EST applies to $\mathrm{C}$ and $\mathrm{R}$ to yield the set of individuals such that their degree of R-ness exceeds everyone else's degree of R-ness.

Heim (1999) formulated two possible hypotheses concerning the way in which the value of the comparison class $C$ is determined. The first option, dubbed "in situ analysis/theory" by Heim, is to assume a uniform syntax-semantics analysis of superlatives, as shown in (3)a-c:

3) a. John bought [the [EST C [expensive ring]]]

b. $[$ [expensive $]]([[$ ring $]]))=\lambda d \lambda x \cdot x$ is a ring $\wedge$ expensive $(x) \geq d$

c. John bought the unique $\mathrm{x}$, such that $\mathrm{x}$ is a ring $\wedge \exists \mathrm{d}[\operatorname{expensive(x)}$ $\geq \mathrm{d} \wedge \forall \mathrm{y}[\mathrm{y} \in \mathrm{C} \wedge \mathrm{y} \neq \mathrm{x} \rightarrow \neg[\mathrm{y}$ is a ring $\wedge$ expensive $(\mathrm{y}) \geq \mathrm{d}]$

Given the identity in LF representations, the differences between the readings of superlatives would be due to the pragmatic computation, which is credited with the power of fixing the value of $\mathrm{C}$ by taking into account contextual information. For our example, the gradable property $\mathrm{R}$ is supplied by the NP [expensive ring] and the comparison 
class is a covert deictic element, which would pick up one of the following values:

4) a. $\mathrm{C}_{\mathrm{ABS}}=\{\mathrm{x}: \mathrm{x}$ is a ring $\}$

b. $\mathrm{C}_{\text {Agent }}=\{\mathrm{x}$ : $\mathrm{x}$ is a ring bought by an individual $\}$

Note that the "in situ" label is a misnomer insofar as the analysis thus named does involve EST raising at LF to a DP-internal position just below THE (capitals indicate that we refer not only to the English the but also to definite articles across languages). Indeed, if EST did not raise, it would have to first combine with the adjective, and the result would then combine with the noun, which would not yield the correct semantics (see Heim 1999: 3). The crucial point is that on the in situ analysis, EST stays inside its host DP.

According to the alternative "scopal" or "movement" analysis (also called "EST-raising" analysis), the difference between the absolute and the relative readings relies on a difference in syntactic scope. On this view, the LF in (3)a would only underlie the absolute reading, whereas on its relative reading, EST would raise out of the DP:

5) John [EST C] [ $\lambda \mathrm{d} \lambda \mathrm{x} \mathrm{x}$ bought [a $\mathrm{d}$-expensive ring]]

Granting that the comparison class is determined by the constituent that is a sister of EST at LF, the comparison class corresponding to (5) is shown in (6):

6) $C=\{x: \exists d[x$ bought a $d$-expensive ring] $\}$

Going back to (5), [ $\lambda \mathrm{d} \lambda \mathrm{x} \mathrm{x}$ bought [a d-expensive ring]] denotes the relation that $\mathrm{x}$ bears to $\mathrm{d}$ iff $\mathrm{x}$ bought a $\mathrm{d}$-expensive ring. By applying the meaning of [C -est] (which we obtain by applying the denotation of EST in (2) to its first argument $\mathrm{C}$ ) to [ $\lambda \mathrm{d} \lambda \mathrm{x} \mathrm{x}$ bought [a d-expensive ring]] we get the property of buying a more expensive ring than any other element of $\mathrm{C}$ bought. On the final step, that property is saturated with John, which means that we ascribe to John the property of having bought a ring that is more expensive than the rings that any other person bought.

In sum, LFs of the form in (5), which are obtained by raising EST out of its host DP and by adjoining it to VP, is able to capture the correct truth conditions of the relative reading of superlatives: according to this LF, EST quantifies not just over expensive rings, but rather over expensive rings bought by somebody. 
Let me stress that on the EST-raising analysis, just as on the in situ analysis, the relative and the absolute readings rely on the same denotation of EST, the one given in (2). The difference between the two readings is due to the difference in the scope of EST, which is determined by the constituent to which EST adjoins at LF, namely NP and VP for absolute and relative superlative readings, respectively (see (5) and (3)a) $)^{1}$.

\section{The details of the movement analysis of relative superlatives}

In the simplified version presented in the previous section, the movement theory of relative superlatives is incomplete, viz. misleading, insofar as it does not mention the fact, clearly acknowledged by Heim (1999) herself, that this analysis involves not just the raising of EST but also the raising of one of the arguments (adjuncts included) of the main predicate. This point will be made explicit in $\$ 2.1$. I will then $(\$ 2.2)$ turn to the well-known problem of raising EST out of a definite DP: since they are islands for movement, definite DPs should block EST. This syntactic problem can be solved by taking into account Szabolcsi's (1986) observation that relative superlatives behave like indefinites in at least some contexts. Given this generalization, the syntactic problem disappears: if indeed relative superlatives are indefinites, they are expected to allow EST raising. But we are left with questions regarding the syntax-semantics interface. How should the indefinite nature of relative superlatives be formally analyzed? Why is the definite article obligatory in overt syntax despite the semantic indefiniteness of relative superlatives? After briefly reviewing previous proposals I will suggest a new analysis, which involves EST raising via Spec,DP correlated with the checking of THE. As a result, THE translates as an existential at the DP level, allowing its uniqueness to be computed at the IP level.

1 The absolute reading of (1) (see 1a) would be read off $3 \mathrm{a}$, which would yield the comparison class in $4 \mathrm{a}$. This amounts to requiring that John bought the most expensive ring out of a contextually salient set of rings. 


\subsection{The raising of the correlate argument}

Let us consider the example in (7), which differs from (1) by the presence of a Beneficiary argument. The crucial point is that this example has not just one, but two possible relative readings, as indicated by the paraphrases in ( $7 b)$ and $\left(7 b^{\prime}\right)$. In order to facilitate the comparison of the paraphrases of (1) and those of (7), I have repeated the absolute reading under the (a) paraphrase (but nothing new will be added here regarding the analysis of this reading) and used (b) and (b') for the two relative readings:

7) John bought the most expensive ring for Mary.
a. Out of all the rings in a given shop John bought the most expensive one for Mary.
b. Out of a given group $G_{1}$ of buyers it's John who bought the most expensive ring for Mary.
b'. Out of a given group $\mathrm{G}_{2}$ of beneficiaries it's for Mary that John bought the most expensive ring.

The problem is that the movement analysis as presented in the previous section (see the LF in (5) and the semantic analysis associated to it) can only account for the (b) reading. In order to get the (b') reading we need to raise Mary first and then to raise [EST C] just below the landing position of the raised Mary:

8) Mary [EST C] [ $\lambda \mathrm{d} \lambda \mathrm{x}$ John bought [a $\mathrm{d}$-expensive ring] for $\mathrm{x}]$.

The corresponding comparison class denotes the set of individuals for whom John bought a d-expensive ring (compare the comparison class corresponding to the (7b) paraphrase, given in (6)):

9) $\mathrm{C}=\{\mathrm{x}: \exists \mathrm{d}[$ John bought a $\mathrm{d}$-expensive ring for $\mathrm{x}]\}$

Thus, in the general case, the so-called "EST-raising analysis" involves not only the raising of EST itself, but also the raising of another constituent, call it the "correlate" of the superlative (Mary in our example). In the LF in (5), which accounts for the (b) reading of (1), the necessity of raising the correlate (John in that case) is obscured by the fact that the correlate is a preverbal subject: assuming that EST can attach to the VP, the preverbal subject-which is external to the VPdoes not need to raise in order to allow the VP-adjoined EST to take a comparison class corresponding to the VP.

In sum, the existence of more than one relative reading clearly indicates that the EST raising hypothesis alone is not sufficient to 
explain the semantics of relative superlatives. Crucial for distinguishing between the (1b) and (1b') readings is the hypothesis that one of the arguments of the main predicate also needs to raise. The form of the comparison class depends on which argument is raised.

\subsection{The (in)definiteness of relative superlatives: EST transits through Spec,DP}

A problem for the raising analysis of EST is that definite DPs constitute an island for movement, and as such they are expected to prevent EST from raising out of the DP. But interestingly, relative superlatives are not genuine semantic definites. As observed by Szabolcsi (1986), relative superlatives (in contrast to absolute superlatives) pass a number of tests that suggest that they are indefinites. Thus, superlative DPs built with relational nouns can appear as objects of have, which patterns with indefinites and contrasts with definites:

10) a. John has the smartest sister.

b. John has a sister.

c. ${ }^{\star} J o h n$ has the sister.

The indefinite-like behavior of relative superlatives is a fact that any analysis should at least encode and ideally explain. According to Szabolcsi's implementation, THE and EST form a discontinuous constituent which can be interpreted either at the N" level (say the NP) or at the $\mathrm{N}^{\prime \prime}$ (say the DP) level, respectively yielding the relative and absolute readings: when [THE EST] sits at the $\mathrm{N}^{\prime \prime}$ level, $\mathrm{D}^{\circ}$ is empty and interpreted as indefinite. This then would allow EST raising.

Heim's (1999: 11) proposal is technically different: "the THE which appears on the surface is semantically vacuous, whereas the determiner that is actually interpreted is a superficially unrealized instance of either the definite or the indefinite article". Heim further assumes that the choice of the indefinite article is mandatory for EST to be able to raise.

These proposals encode the generalization that relative superlatives are semantic indefinites, but they do not explain why they must be marked for definiteness in overt syntax (i.e., have a $\mathrm{D}^{\circ}$ filled with THE rather than with $\mathrm{A}$ ).

In an attempt to answer that question, Krasikova (2012) proposed that at LF the relative superlative THE is part of the DegP constituent, 
and $\mathrm{D}^{\circ}$ is empty, thus allowing it to be either expletive or interpreted as indefinite. This proposal is problematic on at least two grounds. In section 3 below we will see that in Romance languages, THE can indeed be part of DegP, but that nevertheless $\mathrm{D}^{\circ}$ must be filled with a definite article on both absolute and relative readings of quality superlatives. In section 4 we will see that in certain languages, quantity superlatives must lack THE, although in the same languages quality superlatives require THE. These data strongly suggest that THE has a role to play in the syntax-semantics of the relative readings of quality superlatives. In other words, the kind of indefiniteness characteristic of relative superlative DPs must be derived from an overtly realized THE and cannot be derived by inserting an overt indefinite in $\mathrm{D}^{\circ 2}$.

Let me now turn to my own proposal, illustrated in Figure 1. For readability I use a tree representation and I do not indicate the positions in which lambdas are introduced (just below the landing positions of the raised elements):

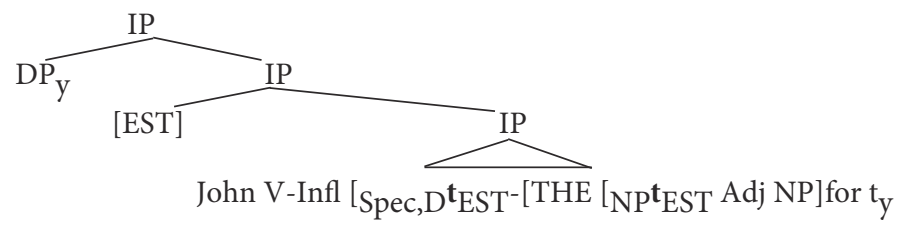

Mary EST John bought [THE d-expensive ring $(\mathrm{x})$ ] for $\mathrm{t}_{\mathrm{y}}$

Figure 1

This configuration differs from Heim's (1999) LF in (8) on two points: (i) EST does not raise in one step, but passes through Spec,DP. This hypothesis has been independently proposed in passing by Giurgea (forthcoming); (ii) $\mathrm{D}^{\circ}$ is filled with THE rather than with an indefinite article. The hypothesis that EST transits through Spec,DP on its way out of the DP lets us expect to find languages in which quality superlatives show up in Spec,DP in overt syntax. In section 3.3 below we will see that this expectation is confirmed in Romanian.

The transition through Spec,DP solves the syntactic problem of raising out of a definite DP: Spec positions are known to offer escape

2 Note that crosslinguistically, relative superlatives never allow an overt indefinite article in $\mathrm{D}^{\circ}$. 
hatches for movement. It is however important to observe that the Spec,DP of a $\mathrm{D}^{\circ}$ filled with a definite article is not accessible to run-ofthe-mill DP-internal constituents: superlatives have a special affinity to definiteness (because they impose uniqueness), and they may well be the only constituents that can access Spec,DP (modulo some checking mechanism that I will not try to make explicit). In sum, the refinement proposed here solves the syntactic side of the problem: EST can raise out of a definite DP because EST can access Spec,DP.

The hypothesis of EST raising via Spec,DP opens the way to a better understanding of the semantic indefiniteness of definite marked superlatives. We may thus assume that the checking of THE at the point at which EST passes through Spec,DP results in changing the contribution of THE to the semantic computation: a "checked" THE would translate as an existential quantifier at the DP level, the computation of its uniqueness being taken over by the raising EST and being computed at the final IP-adjoined position of EST.

This suggestion offers a "dynamic syntactic" implementation (derivational syntactic approaches, and in particular checking theory, can be viewed as dynamic syntax, as opposed to representational approaches) of relative superlatives. They do not start out as indefinite (as in all of the proposals just reviewed) but become indefinite at the lower DP-level (due to the checking of THE, which translates as an existential) and moreover they preserve their definiteness at the higher IP-level, because their uniqueness can be computed at that level: in our example, the external argument of the superlative DP is the unique most expensive ring bought by John for somebody.

Note now that the quantificational status of relative superlative DPs postulated in the analysis proposed here forces it to raise at LF. Hence, the complete syntactic derivation is as shown in Figure 2:

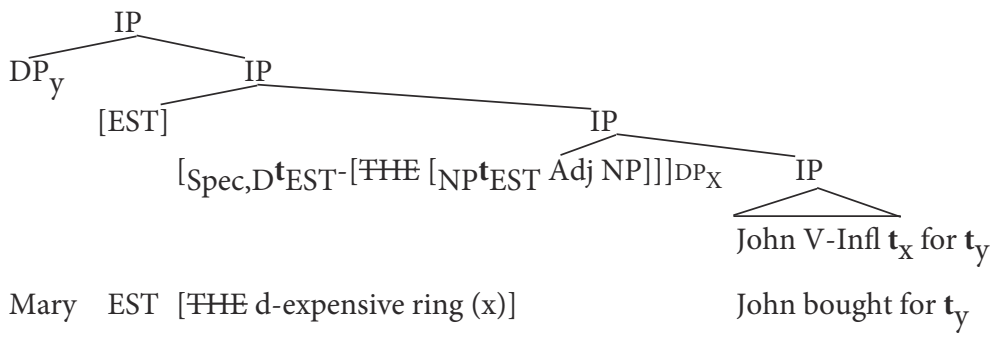

Figure 2 
Thus, under its fully explicit representation, the so-called "ESTraising" analysis involves three, rather than just one movement, which apply in the following order: (i) raising of the correlate $\left(\mathrm{DP}_{\mathrm{y}}\right.$ in Figure (2)); (ii) raising of the superlative $\mathrm{DP}\left(\mathrm{DP}_{\mathrm{y}}\right.$ in Figure (2)) just below the raised correlate; (iii) raising of EST, which attaches immediately above the raised superlative DP.

By applying the denotation of EST (see (2)) to the LF in Figure (2) we get the following truth conditions:

11) $\exists x[x$ is a ring $\wedge$ John bought $x$ for Mary $\wedge \exists d[$ expensive $(x) \geq d \wedge \forall y[y$ $\in \mathrm{C} \wedge \mathrm{y} \neq$ Mary $\rightarrow \neg \exists \mathrm{z}[\mathrm{z}$ is a ring $\wedge$ John bought $\mathrm{z}$ for $\mathrm{y} \wedge$ expensive $(\mathrm{z})$ $\geq \mathrm{d}]]]]$

\subsection{Conclusions: obligatory definite marking in relative readings of quality superlatives}

My proposal makes sense of the following generalization:

12) The relative reading of adnominal ${ }^{3}$ quality superlatives requires the presence of THE 4 .

This generalization is interesting insofar as it distinguishes relative readings of adnominal quality superlatives from a number of superlative configurations that do not require the definite article: (i) quantity superlatives may lack THE (see section 4 below); (ii) we may find examples of indefinite-marked superlatives (e.g., This class has a best student, see Herdan \& Sharvit 2006); (iii) superlatives in predicate positions may lack THE; (iv) adverbial superlatives may lack THE; (v) Pancheva \& Tomasziewicz (2012) identified for Slavic languages

3 For reasons of space superlatives in predicate positions have been left aside in this paper. But interestingly, contra Matushansky (2008), it can be shown that the presence of THE is not required, and in fact banned whenever a superlative adjective is "bare" in predicate positions (THE appears whenever the superlative adjective is embedded in a DP with a null pronoun). This generalization fits with the proposal in this paper: whenever quality superlatives are embedded in a DP, $\mathrm{D}^{\circ}$ must be filled with a definite article and EST transits through Spec,DP in order to raise out of the DP. However, superlative adjectives do not need to be embedded in a DP, and when they are not, THE is absent.

4 As shown in $\$ 3.3$ below, Romanian offers an interesting refinement of this generalization. In this language, prenominal superlative adjectives may occur in Spec,DP at S-structure, and this bans THE from showing up in $\mathrm{D}^{\circ}$ (arguably due to a doubly-filled D filter, comparable to the doubly filled Comp filter). 
a "DP-internal focus" reading of superlatives and they showed that in Bulgarian this reading requires lack of THE (compare the absolute and the canonical relative readings, both of which require THE).

In the limits of this article, I will only be able to discuss quantity superlatives (see section 4), leaving the points in (ii)-(v) for another occasion.

\section{Where is THE in Romance superlatives?}

In this section we will examine Romance languages, which are alike in that the superlative meaning is expressed by sequences in which THE is followed by the adjective preceded by the comparative marker (notated ER). As we will see, this common pattern corresponds to several structural configurations (depending on the language and on the pre- or postnominal position of the adjective): (i) THE sits in $\mathrm{D}^{\circ}$ and ER in DegP; (ii) THE and ER are both in DegP and $\mathrm{D}^{\circ}$ is filled either by another occurrence of THE or by a null element. This short presentation may let the knowledgeable reader expect a decompositional analysis of superlatives along the lines initiated by Bobaljick (2012) (see Dunbar \& Wellwood (2016) and Caha et al. (2019) for alternatives), but this issue will be left aside here. My main interest in this paper is not the internal make-up of superlatives but rather the relation between superlative-marked elements (be they bound morphemes, free standing morphemes or phrases) and the definite marking in $\mathrm{D}^{\circ}$. As we will see, superlative readings of quality adjectives-and in particular relative superlative readings-expressed by comparative morphosyntax require $\mathrm{D}^{\circ}$ to be filled with THE unless [DegPTHE ER] sits in Spec,DP (as is the case with Romanian prenominal superlatives). Romance languages thus show that the generalization in (12) holds not only in languages with a dedicated superlative morpheme EST, but also in languages that lack EST and instead have a superlative-dedicated DegP (French and Romanian) and even in languages that lack superlative-dedicated DegPs (Italian and Ibero-Romance). 


\subsection{Postnominal superlatives in French and Romanian}

Let us consider French postnominal superlatives:

13) Jean a lu $\left[\left[_{\left.D^{\text {ole }}\right]}\right]\right.$ livre [[ ${ }_{\text {DegP }}$ le plus long $\left.\left.]\right]\right]$. John has read THE book THE ER long. John read the longest book.

It is clear that the second occurrence of le cannot be assumed to sit in $\mathrm{D}^{\circ}$ but instead is part of a DegP of the form [DegPTHE ER] that has a superlative meaning, hence the notation [SupPTHE ER], which I will use for readability.

Romanian is like French in that the strong definite article cel preceding the comparative co-occurs with a definite-marked noun:

14)

$$
\begin{gathered}
{\left[D P\left[D^{\circ} \emptyset\right]\right]_{\text {NPcartea }}} \\
\text { book-THE }
\end{gathered}
$$

The noun cartea carries the suffixal definite article $-a$ "THE $\mathrm{FSG}$ ", the $\mathrm{D}^{\circ}$ position is empty (as a result of the suffixation of the article) and the strong definite article cea "THE FSG" forms a constituent with the adjective preceded by the comparative marker mai "ER"6.

In what follows I will show that superlative-dedicated phrases of the form [SupPTHE ER] can be analyzed on a par with the superlative morpheme [EST], by extending the proposal made in section 2 . To this end, let us consider the French and Romanian examples that are the counterparts of the English example in Figure (1):

15) a. Jean a acheté la bague la plus chère pour Marie.

b. Ion a cumpărat inelul cel mai scump pentru Maria. Ion has bought ring-the THE ER expensive for Maria John has bought the most expensive ring for Maria.

5 Note that like the English more, the French plus is a suppletive comparative form of beaucoup "many/much") that also functions as a comparative morpheme in analytic comparatives.

6 The Romanian mai is not a suppletive form of mult "much". Inside the DP, it is exclusively a comparative marker; outside the DP, it can be used adverbially in which case it marks additivity, meaning "again" or "already", depending on the context. 


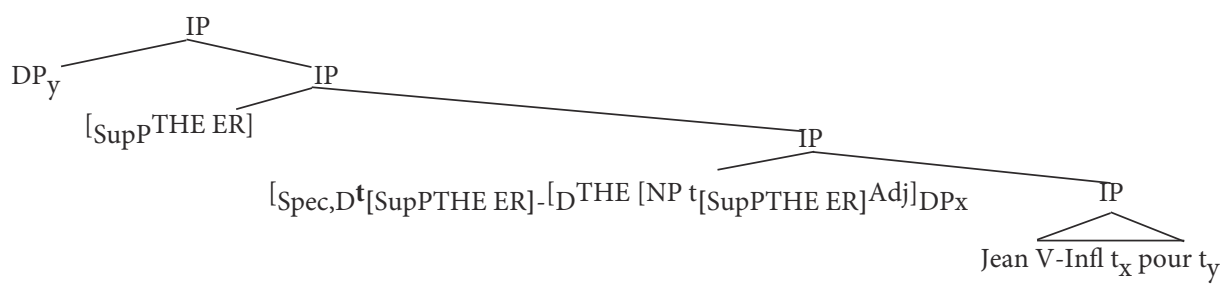

Figure 3

a. Marie ${ }_{\mathrm{y}}$ [la plus] [ $\mathrm{t}_{\text {[la plus }}$ la bague $\left.(\mathrm{x}, \mathrm{d}) \mathrm{t}_{\text {[la plus }}\right]^{\text {chère }} \mathrm{DPx}$ Jean a acheté $t_{x}$ pour $t_{y}$

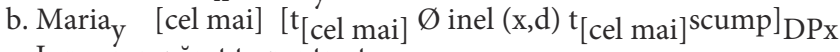
Ion a cumparrat $t_{x}$ pentru $t_{y}$

As already announced in the introduction of this section 3, I will not try to build the superlative meaning of [SupPTHE ER] from the meanings of THE and ER. I will simply assume that the denotation of [SupPTHE ER] is identical to the denotation of EST (see 2).

\subsection{Postnominal superlatives in Italian}

The crucial role played by the definite article in $\mathrm{D}^{\circ}$ for the semantics of superlatives is particularly clear in Italian (and Ibero-Romance, not illustrated here), which lacks not only dedicated superlative morphemes of the EST type but also dedicated superlative phrases of the form [SupPTHE ER]. In these languages, comparative forms are necessarily bare (i.e., they are not preceded by THE) but they can be interpreted as superlatives provided that the comparative is embedded inside a definite DP (or inside a relative clause, not illustrated here) ${ }^{7}$ :

16) [DP[D' [Dola] [ragazza] [SupPpiù alta]]] According to Kayne (2008) and Loccioni (2018, to appear), Italian postnominal superlatives are like their French counterparts modulo the fact that THE is null inside SupP and because of its being null it needs

7 In other contexts, e.g., in predicate positions, Italian comparatives cannot take relative superlative readings, in contrast to French and Romanian adjectives preceded by THE ER. 
to be legitimated by the definite article of the DP (or by the wh-element of a relative clause, again not illustrated here) $)^{8}$ :

17) [DP[D' [Dola] [ragazza] [SupP $\varnothing$ più alta]]]

An alternative would be to assume that the null element $\varnothing$ inside [SupP $\varnothing$ più alta] is a silent element with the semantics of "than all others"; the definite article of the DP would provide the index that is needed in order to compute the set of "all others".

The choice between these possibilities is not relevant for our main purposes. What matters is that Italian postnominal bare comparatives are interpreted as superlatives when occurring inside definite DPs and that they allow both the absolute and relative readings. It is easy to see that our analysis of the relative reading of superlatives can account for why that reading is allowed in a configuration like (17): all we need to assume is that [SupP $\varnothing$ piu alta] raises to Spec,DP and from there outside the superlative DP.

\subsection{Prenominal superlatives across Romance}

According to Kayne (2008) and Loccioni (2018, to appear), in examples of the type in (18), where the superlative is prenominal, the definite article sits in $\mathrm{D}^{\circ}$, as shown in (19):

18) Jean a lu le plus long livre.

John has read THE MORE long book

John read the longest book.

19) Jean a lu [[ $D^{\text {ole }] ~[[S u p p p l u s ~ l o n g] ~ l i v r e]] . ~}$

This bracketing is supported by examples like (23), where the cardinal intervenes between $l e$ and the comparative, which clearly indicates that le sits in $\mathrm{D}^{\circ}$ :

20) Jean a lu $\left[\left[_{D^{\text {oles }}}\right]\right.$ deux [ DegPplus longs] livres. John has read THE two more long books John read the two longest books.

8 The representation in (17) is much simpler than Kayne's (2008) and even simpler than Loccioni's (2018). For reasons of space and also because the details of the syntactic representation are not relevant to our main goals, I will not review the proposals made by these authors. All that matters is that they assume for Italian a null element corresponding to THE inside a superlatively-interpreted DegP notated [SupPØ ER]. 
The structure in (19) has been argued to underlie prenominal superlatives not only in French, but also in Italian and Ibero-Romance (Loccioni 2018):

21) [[ $\left.\mathrm{D}^{\text {oil }}\right]$ [[SupP più lungo] libro $\left.]\right]$

Romanian differs from French and Italian in that prenominal superlatives have the same internal structure as postnominal superlatives, i.e., the THE that precedes ER Adj does not sit in $\mathrm{D}^{\circ}$ but instead is part of a SupP constituent:

22) [DP[Spec,DP [SupPcea mai lungă $\left.]]\left[D^{\prime}\left[D^{\circ} \oslash\right]\left[N^{\text {carte }}\right]\right]\right]$ [DP[Spec,DP [SupPTHE MORE long]] [D'[ $\left.{ }^{\circ} \varnothing\right]$ [NPbook]]]

Empirical evidence in favor of the constituency structure in (22) - in which [SupPcea mai lungă] sits in Spec, DP-can be found in Giurgea (2013), Cornilescu and Giurgea (2013), Dobrovie-Sorin and Giurgea (2021, Chapter 2: section 5). Note in particular that the Romanian counterpart of the word order in (20) is impossible. The only possibility is to have the numeral follow the superlative:

23) *cele două mai lungi cărți

THE $_{\mathrm{PL}-\mathrm{F}}$ two $_{\mathrm{F}}$ more long $\mathrm{PL}$ books

b. cele mai lungi două cărți

THE $_{\mathrm{PL}-\mathrm{F}}$ more long $\mathrm{PL} \mathrm{two}_{\mathrm{F}}$ books the longest two books

Since numerals are very high inside the DP, the word order in the $\mathrm{b}$ example supports the view that the superlative adjective sits in Spec,DP rather than in some lower position specialized for prenominal superlatives.

The configuration in (22) provides interesting evidence that supports the hypothesis of the LF raising of [SupPTHE ER] to Spec,DP in those configurations in which at S-structure [SupPTHE ER] sits in the postnominal position. It is also interesting to observe that the overt realization of the element in $\mathrm{D}^{\circ}$ depends on whether [SupPTHE ER Adj] sits in Spec,DP at surface structure (in which case-due to the doubly filled Det filter-a null element is inserted in $\mathrm{D}^{\circ}$ ) or instead [SupPTHE ER] transits through Spec,DP at LF (in which case THE must be inserted in $\mathrm{D}^{\circ}$ ). But in both cases, the element in $\mathrm{D}^{\circ}$ (be it null or THE) is interpreted as a canonical definite in absolute readings and as an "existential definite" in relative readings (see Section 2.2 above). 


\subsection{Conclusions}

The data presented in this section show that the syntactic structure of French and Romanian postnominal superlatives is crucially different from that of Italian and Ibero-Romance, where THE cannot be part of SupP (Kayne 2008, Loccioni 2018). This crosslinguistic difference among Romance languages is arguably due to a grammaticalization path that leads from the Italian and Ibero-Romance pattern to the French and Romanian pattern. In contrast to Germanic and Slavic languages, which had developed superlative forms before the definite article was introduced, Romance languages lacked superlative forms and used the comparative with a superlative meaning 9 . When the definite article was introduced in these languages, it was sitting in $\mathrm{D}^{\circ}$, as it does until today in Italian and Ibero-Romance. The Romanian and French pattern is due to some kind of reanalysis/restructuring that resulted in THE forming a constituent with the comparative.

The semantic analysis I have proposed is not sensitive to the variety of syntactic configurations that superlative constituents may take. Thus, the relative superlative reading of quality adjectives relies on [Sup EST], [SupPTHE ER] or [SupP $\varnothing \mathrm{ER}]$ ] raising to the Spec,DP of [ $\left.\mathrm{D}^{\circ} \mathrm{THE}\right]$, which is the decisive factor for a relative reading to be possible. This analysis is supported by Romanian prenominal superlatives, in which [SupPTHE ER] sits in Spec,DP at S-structure.

In the next section I will show that in several unrelated languages, the relative reading of the superlative of MANY/MUCH is incompatible with [ $\mathrm{D}^{\circ \mathrm{THE}}$. I will propose that when [EST] or [THE ER] are associated with MANY/MUCH, $\mathrm{D}^{\circ}$ is filled with a null element that is invisible to the semantic representation, which means that it does not even translate as an existential (unlike what happens under our analysis for the relative readings of quality superlative, see Figure (1)-(13)).

9 As observed by Ion Giurgea (p.c.), this conjecture needs to be supported by diachronic data showing that the superlative disappeared in late Latin before the definite article was introduced in early Romance languages. Neither Ion Giurgea nor myself know of any investigation of the relative datings of the two phenomena (disappearance of the Latin superlative and introduction of definite articles in Romance). 


\section{Quantity Superlatives}

It has long been observed that the superlative of MANY/MUCH does not have an absolute reading (Gawron 1995) ${ }^{10}$. But most, maybe all the existing literature analyzes the relative reading of MOST on a par with the relative readings of quality superlatives. This view cannot explain why in a number of languages THE is banned with MOST although it is required with quality superlatives.

\subsection{Absence of $\left[D^{\circ} T H E\right]$ with quantity superlatives in languages with EST}

In several unrelated languages, the superlative MOST bans the definite article. This generalization was pointed out by Coppock \& Josefson (2015), Coppock \& Strand (2016) and Coppock (2019) for mainland Scandinavian languages, illustrated below with a Swedish example:

24) Gloria har besökt flest kontinenter.

Gloria has visited most continents

Gloria visited the most continents (more continents than anybody else).

(Coppock \& Josefson 2015: ex. 3-4)

The lack of THE for the superlative reading of MOST contrasts with the obligatory use of THE for the proportional MOST (not illustrated here) and with the use of THE with the relative superlative readings of quality adjectives ${ }^{11}$ :

25) Den stör-st-a tall-en blev ner-skuren.

the big-est-W $\mathrm{W}^{12}$ pine-DEF became down-cut

The largest pine was cut down.

10 Hackl (2009) proposed that an LF representation comparable to that of absolute superlatives underlies the proportional reading of MOST. Evidence against Hackl's widely assumed analysis can be found in Dobrovie-Sorin \& Giurgea (2021), where several types of proportional MOST are distinguished and the distribution of THE for each of them is examined.

11 The definite article is generally required with quality superlatives in Swedish, but Coppock \& Josefson (2015) and Coppock (2019) observed certain cases in which the article is optional. The difference with the superlative MOST is nevertheless clear, since for MOST the article is banned.

$12 \mathrm{~W}$ notates the weak declension, which is used in adjectives preceded by the definite article. 
Dobrovie-Sorin \& Giurgea (2021) observed that Basque resembles Scandinavian, modulo the fact that the article is not the canonical definite, but a "general" article. Like in Scandinavian, the article is obligatorily absent with the superlative MOST and obligatorily present with the proportional MOST on the one hand, and with quality superlatives on the other hand. A discriminating distribution of the definite article can also be observed in Bulgarian, where the proportional reading of MORE requires THE, and the relative superlative reading is mostly expressed by MOST without THE (see Pancheva 2015). And again, THE is obligatory with the "canonical" relative reading of quality superlatives ${ }^{13}$.

\subsection{Absence of $\left[\mathrm{D}^{\circ} \mathrm{THE}\right]$ with quantity superlatives in French and Romanian}

The French le plus "THE MORE" meaning "the most" resembles quality superlatives in that it is built with a comparative preceded by the definite article:

26) Jean a lu le plus de livres.

John has read THE MORE of books

John read the most books.

Nevertheless, le plus "the most" crucially differs from quality superlatives in that it can never be postnominal and moreover requires (on a par with the positive form beaucoup "much, many") a pseudopartitive configuration (i.e., the NP is introduced by $d e$ ):

27) a. $20 \mathrm{~g}$ de beurre

$20 \mathrm{~g}$ of butter

b. beaucoup de beurre/d'enfants

much of butter/of children

c. le plus de beurre/d'enfants

THE MORE of butter/of children the most butter/children

According to Schwarzschild (2006), pseudo-partitives involve the projection of a special functional head labelled $\mathrm{Mon}^{\circ}$. I will use Solt's

13 Pancheva \& Tomaszewicz (2012) observed an interesting contrast between the presence vs. absence of THE with canonical relative superlatives vs. another type of relative reading of superlatives, which arises in the presence of DP-internal focus (in the terms used in this paper, the relevant reading involves a DP-internal correlate). 
(2009) label $\mathrm{Meas}^{\circ}$, which indicates in a more transparent way that this head hosts measure functions, in particular the cardinality function (in those configurations in which Spec, Meas is filled with MANY (rather than with MUCH)). I will assume that the presence of pseudopartitive morphosyntax with le plus indicates that this element sits in Spec, Meas ${ }^{14}$ :

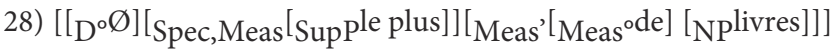

The fact that le "the" does not sit in $\mathrm{D}^{\circ}$ is indicated by its invariable form. Note however that agreement in gender and number with the main noun does not mean that the definite article necessarily sits in $\mathrm{D}^{\circ}$ : see in particular postnominal superlatives (e.g., la fille la plus grande

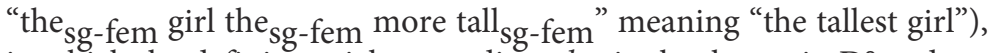
in which the definite article preceding plus is clearly not in $\mathrm{D}^{\circ}$ and yet it does agree with the head noun. Thus, the invariability of le "the" inside le plus "the most" is arguably more related to the fact that it sits in Spec,Meas: note that beaucoup "much" itself is invariable.

In sum, from the point of view of their internal make-up, French quality postnominal superlatives and the quantity superlative le plus "the most" are alike: a SupP of the form [THE ER] precedes the positive form of the adjective (recall that plus is both ER and a suppletive form of ER+beaucoup). However, the two types of superlatives differ regarding their syntactic position (postnominal modifier position and Spec,Meas, respectively).

In section 3.3 I have used examples built with cardinals (see (23)) as evidence in favor of the hypothesis that Romanian prenominal quality superlatives sit in Spec,DP. This does not mean that quantity superlatives themselves sit in Spec,DP. It seems instead reasonable to generalize what we have observed for French, namely that it is the "quantity" status rather than the "superlative" status that determines the position in which cel mai mult/cei mai mulți "THE MORE

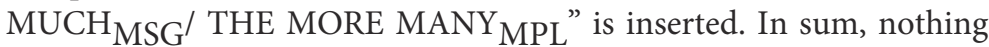
goes against assuming that cel mai mult/cei mai mulți are merged in Spec,Meas, on a par with the French le plus.

14 This does not mean, however, that a pseudo-partitive configuration is needed for any constituent that sits in Spec,Meas. In many languages cardinals do not trigger pseudo-partitivity but nevertheless they arguably sit in Spec,Meas. 


\subsection{Italian and Ibero-Romance}

In section 3.2 above we have seen that in Italian and IberoRomance superlative meanings are obtained by using a "bare" (i.e., non preceded by THE) comparative adjective embedded inside a definite DP or inside a relative clause. For the superlative of MANY/MUCH the first option is unavailable, which is expected if indeed superlatives of quantitatives are incompatible with a definite THE in $\mathrm{D}^{\circ}$. Embedding inside a relative clause is the only possibility for piu "more" to mean "(the) most":

29) Gianni è quello che ha $\left({ }^{*} i\right)$ più amici (tra tutti i suoi colleghi). (It.) Gianni is the-one who has (the) more friends (among all the his colleagues)

Gianni is the one who has the most friends (among all his colleagues).

\subsection{The semantic composition}

We have so far examined data from several languages that show that $\left[\mathrm{D}^{\circ \mathrm{THE}}\right]$ is banned with quantity superlatives and we have proposed that this state of facts can be captured by assuming that quantity superlatives have the same syntax as measure phrases, as well as MANY/MUCH: they sit in Spec,Meas and $\mathrm{D}^{\circ}$ is filled with a null element (as is also the case for bare plurals, bare mass nouns, indefinite DPs built with numerals or pseudo-partitive DPs built with measure phrases). Given such a syntactic configuration, in an example like (24) nothing stays in the way of EST raising out of the DP, which yields the LF in (Figure 4):

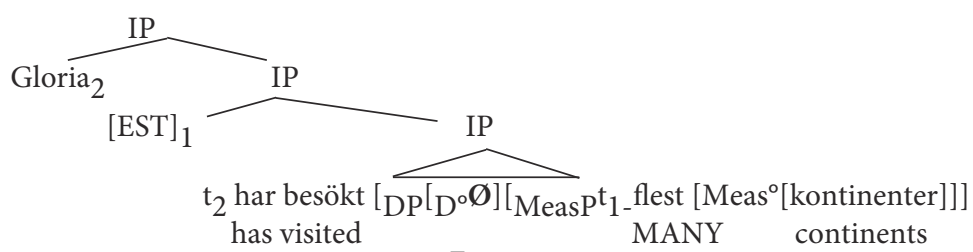

Figure 4

This differs from the derivation we proposed for the relative readings of quality superlatives in that EST does not transit through Spec,DP: it does not need to because the null element in $\mathrm{D}^{\circ}$ is base-generated 
as a null indefinite-like determiner, which allows the raising of EST in one step. Let me further suggest that the null $\mathrm{D}^{\circ}$ that takes MeasP as a complement is genuinely invisible for the semantic computation: unlike the "checked THE" of quality superlatives (see the LFs Figure (1) or Figure (3)), the $\left[D^{\circ} \varnothing\right]$ of quantity superlatives does not translate as an existential: I assume that DPs that embed quantity superlatives are neither referential nor existential quantifiers but rather weak indefinites, EST itself functioning as a degree quantifier. Under the view that weak indefinites are pseudo-incorporated (see van Geenhoven 1996, a.o.), this means that no individual variable is present at LF.

Given the LF configuration in Figure (4) the comparison class is (30):

30) $\mathrm{C}=\{\mathrm{x}: \exists \mathrm{d}[\mathrm{x}$ visited $\mathrm{d}$-many continents $]\}$

By applying the denotation of EST in (2), we obtain the following LF representation:

31) $\exists \mathrm{d}[$ Gloria visited d-many continents $\wedge \forall \mathrm{x}[\mathrm{x} \in \mathrm{C} \wedge \mathrm{x} \neq$ Gloria $\rightarrow \neg \mathrm{y}$ visited d-many continents]

In this representation, [d-many continents] is not an existentially quantified DP (compare again relative quality superlative DPs, which must be analyzed as existentially quantified) and no variable over the groups over which [d-many continents] ranges is present. Correspondingly, no unique group of continents is required for the sentence to be true.

\subsection{When [ $\left.\mathrm{D}^{\circ} \mathrm{THE}\right]$ co-occurs with MOST}

In this section we have so far examined DPs in which MOST (expressed by either EST or [THE ER]) sits in Spec,Meas and $\mathrm{D}^{\circ}$ is null. This generalization seems to be disconfirmed in languages such as English (or German), in which MOST co-occurs with a definite article:

32) Who read the most books?

And yet, despite the presence of THE, the most is interpreted exactly on a par with the bare flest in Scandinavian: no uniqueness is required for the group to which [DPthe most NP] refers. Thus, in an example like (33) we may allow Gloria to visit one or more continents several times:

33) During the last ten years, Gloria visited the most continents. 
Against the background of the proposal made in this paper, the most needs to be analyzed as a complex constituent sitting in Spec,Meas (at least at LF, but possibly also at S-structure). Evidence in favor of this hypothesis can be found in Wilson (2018):

34) $\left[\mathrm{D}^{\circ} Ø\right]\left[\right.$ Spec,Meas[DegPthe most]][Meas'Meas ${ }^{\circ}$ [NPboys]]

I leave this for further research.

\section{References}

BOBALJIK, J. D. (2012), Universals in Comparative Morphology: Suppletion, Superlatives, and the Structure of Words, Cambridge, MA: MIT Press.

CAHA P., DE CLERCQ K. \& VANDEN WYNGAERD G. (2019), The fine structure of the comparative, Studia Linguistica 73: 3, 470521.

COPPOCK E. (2019), Quantity Superlatives in Germanic, or "Life on the Fault Line Between Adjective and Determiner", Journal of Germanic Linguistics 31: 2, 109-200.

COPPOCK E. \& JOSEFSON C. (2015), Completely bare Swedish superlatives, in Csipak E. \& Zeijlstra H. (eds), Proceedings of Sinn und Bedeutung 19, University of Göttingen, 179-196.

COPPOCK E. \& STRAND L. (2019), Most vs. the most in languages where the more means most, in Aguilar A., Pozas Loyo J. \& Vázquez-Rojas Maldonado V. (eds.), Definiteness across languages, Berlin, Language Science Press, 371-417.

CORNILESCU A. \& GIURGEA I. (2013), The adjective, in DobrovieSorin C. \& Giurgea I. (eds), A Reference Grammar of Romanian. I: The Noun Phrase, Amsterdam / Philadelphia, John Benjamins, 355-529.

DOBROVIE-SORIN C. \& GIURGEA I. (2021), Majority quantification and quantity superlatives. A crosslinguistic analysis of Most, Oxford University Press.

DUNBAR E. \& WELLWOOD A. (2016), Addressing the "two interface" problem: Comparatives and superlatives, Glossa: A Journal of General Linguistics, 1: 1, 5. <http://doi.org/10.5334/gjgl.9>.

GAWRON J. M. (1995), Comparatives, Superlatives, and Resolution, Linguistics and Philosophy 18, 333-380.

GEENHOVEN V. van (1996), Semantic Incorporation and Indefinite Descriptions: Semantic and Syntactic Aspects of Noun 
Incorporation in West Greenlandic, PhD Diss., University of Tübingen.

GIURGEA I. (2013), The Syntax of Determiners and Other Functional Categories, in Dobrovie-Sorin C. \& Giurgea I. (eds), A Reference Grammar of Romanian. I: The Noun Phrase, Amsterdam / Philadelphia, John Benjamins, 99-108.

GIURGEA, I. (forthcoming), Two types of quantity relative superlatives, in Mihaela Tănase-Dogaru, Alina Tigău and Mihaela Zamfirescu (eds.), (De)constructing language structure and meaning, Cambridge Scholar Publishing.

HACKL M. (2009), On the grammar and processing of proportional quantifiers: most versus more than half, Natural Language Semantics 17, 63-98.

HEIM I. (1985), Notes on Comparatives and related matters. Ms., UTexas.

HEIM I. (1999), Notes on Superlatives. Unpublished manuscript, MIT, downloadable from <http://semanticsarchive.net/Archive/ TI1MTlhZ/>.

HERDAN S. \& SHARVIT Y. (2006), Definite and nondefinite superlatives and NPI licensing, Syntax 9, 1-31.

KAYNE R. S. (2008), Some preliminary comparative remarks on French and Italian definite articles, in Freidin R., Otero C. P. \& Zubizaretta M. L. (eds), Foundational Issues in Linguistic Theory: Essays in Honor of Jean-Roger Vergnaud. Cambridge (MA) / London, 291-321.

KRASIKOVA S. (2012), Definiteness in superlatives, in Aloni M., Kimmelman V., Roelofsen F., Sassoon G. W., Schulz K. \& Westera M. (eds), Logic, language and meaning, Heidelberg, Springer, 411-420.

LOCCIONI N. (2018), Getting "the most" out of romance, Ph.D., University of California, Los Angeles.

LOCCIONI N. (to appear), The syntax of superlative phrases in Romance, in Vogel I. (ed.), Romance Languages and Linguistic Theory 16. Selected papers from the 47th Linguistic Symposium on Romance Languages (LSRL), Newark, Delaware, Amsterdam / Philadelphia, John Benjamins, 172-186.

MATUSHANSKY O. (2008), On the attributive nature of superlatives, Syntax 11: 1, 26-90.

PANCHEVA R. (2015), Quantity superlatives: the view from Slavic and its crosslinguistic implications, <https://pancheva.github. io/papers/P(2015)CLS.pdf $>$. 
PANCHEVA R. \& TOMASZEWICZ B. (2012), Cross-linguistic Differences in Superlative Movement out of Nominal Phrases, in Arnett N. \& Bennett R. (eds), Proceedings of the $30^{\text {st }}$ West Coast Conference on Formal Linguistics, Somerville (MA), Cascadilla Proceedings Project, 292-302

SCHWARZSCHILD R. (2006), The role of dimensions in the syntax of noun phrases, Syntax 9: 1, 67-110.

SOLT S. (2009), The semantics of adjectives of quantity, $\mathrm{PhD}$, The City University of New York.

SZABOLCSI A. (1986), Comparative superlatives, MIT Working Papers in Linguistics 8, 245-265.

WILSON E. C. (2018), Amount Superlatives and Measure Phrases. $\mathrm{PhD}$, The City University of New York. 